\title{
Isolation of Mannooligosaccharides Corresponding to Antigenic Determinants of Pathogenic Yeast Candida catenulata Cell Wall Mannan
}

\author{
Hidemitsu Kobayashi ${ }^{1}$, Susumu Kawakami ${ }^{1}$, Yukiko Ogawa ${ }^{1}$, Nobuyuki Shibata ${ }^{2}$, Shigeo Suzuki ${ }^{3}$ \\ ${ }^{1}$ Laboratory of Microbiology, Faculty of Pharmaceutical Science, Nagasaki International University, Sasebo, Nagasaki, Japan \\ ${ }^{2}$ Department of Infection and Host Defense, Tohoku Pharmaceutical University, Sendai, Miyagi, Japan \\ ${ }^{3}$ Sendai Research Institute for Mycology, Sendai, Miyagi, Japan \\ Email: h-kobaya@niu.ac.jp
}

Received March 11, 2013; revised April 14, 2013; accepted May 14, 2013

Copyright (C) 2013 Hidemitsu Kobayashi et al. This is an open access article distributed under the Creative Commons Attribution License, which permits unrestricted use, distribution, and reproduction in any medium, provided the original work is properly cited.

\begin{abstract}
To investigate the chemical structure of cell wall mannan of pathogenic yeast, Candida catenulata IFO 0745 strain, which possess the epitopes of antigenic factors 1, 9, and 34 to genus Candida, we previously performed the two-dimensional nuclear magnetic resonance (NMR) analysis of this mannan, Fr. C, without the need for harsh procedures. In this study, three oligosaccharides, biose, triose, and tetraose, and mannose were isolated from Fr. C by acetolysis. The results of NMR analysis indicate that the chemical structures of these oligosaccharides were identified to Man 1 1-2Man,

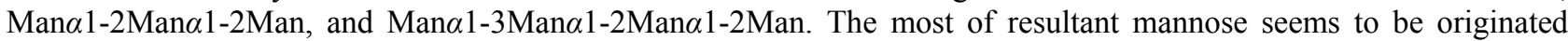
from the $\alpha-1,6$-linked mannan backbone which is recognized by antiserum to factor 9 . The inhibition assay of slide agglutination reaction between Fr. C and antigenic antibodies using three oligosaccharides indicate that the Man $\alpha 1$ 2Man 1 1-2Man and Man $\alpha 1-3$ Man $\alpha 1-2 M a n \alpha 1-2 M a n$ possess domains corresponding to immunodominants of antigenic factors 1 and 34 , respectively.
\end{abstract}

Keywords: Cell Wall Mannan; Antigenic Factor; Candida catenulata; Acetolysis; Oligomannosidic Epitope

\section{Introduction}

Ten rabbit antibodies to antigenic factors of genus Candida (abbreviated as FAbs) were developed to identify clinical isolates from the patients with candidiasis by Fukazawa et al. [1] and Tsuchiya et al. [2,3]. We have reported the structure of cell wall mannans of genus Candida, for examples, C. albicans [4,5], C. tropicalis [6], C. guilliermondii [7], C. glabrata [8], and C. lusitaniae [9]. The determinants of antigenic factors 1,9 , and 34 to genus Candida were linear $\alpha$-1,2-linked oligomannosyl side chains [10], linear backbone consisting of $\alpha$ 1,6 linkage [11,12], and linear oligomannosyl side chains containing a non-reducing terminal $\alpha-1,3$ linkage [12], respectively. On the other hand, the antigenic determinants of factors 5 and 6 correspond to two kinds of $\beta-1,2$ linkage-containing side chains, a homologous series of $\beta$-1,2-linked oligomannosyl side chains [13], side chains composed of $\beta-1,2$ and $\alpha-1,2$ linkages [14], respectively.

In carbohydrate chemistry, acetolysis is the one of the important procedures for the selective cleavage of glycol- sidic linkages, and was frequently used for the structural and immunochemical studies of various yeast mannans $[15,16]$, and for the preparation of various substrates for enzymes in biosynthetic study of yeast mannans $[17,18]$.

Candida catenulata is an opportunistic pathogen for responsible for candidiasis, and its cell wall mannan assumes the antigenicity of the cell surface. In the previous paper [19], the purified mannan obtained from NBRC 0745 (formerly IFO 0745) strain of this species, was utilized for the complete assignment of the nuclear magnetic resonance chemical shifts of all mannose residues in this molecule. In the present immunochemical study of C. catenulata mannan, we adopted acetolysis to obtain oligosaccharides corresponding to determinants of antigenic factors from the parent mannan.

\section{Materials and Methods}

\subsection{Strains and Culture}

Candida catenulata NBRC 0745 (formerly IFO 0745) 
was obtained from the Biological Resource Center, National Institute of Technology and Evaluation, Japan. This strain was cultivated in the yeast extract-Sabouraud's liquid medium $[0.5 \%(\mathrm{w} / \mathrm{v})$ yeast extract, $1 \%(\mathrm{w} / \mathrm{v})$ peptone, and $2 \%(\mathrm{w} / \mathrm{v})$ glucose] at $27^{\circ} \mathrm{C}$ for $72 \mathrm{hr}$ on a reciprocal shaker.

\subsection{Preparation of Mannans}

Mannan were extracted with hot-water and precipitated with Fehling solution [4]. The purified mannan obtained from the cells of the $C$. catenulata strain was designated Fr. C. The yields of Fr. C was $8.0 \%$ of the dry cell weight.

\subsection{Acetolysis of Fr. C}

Acetolysis under conventional conditions was carried out as described previously [20] by modifying the method of Kocourek and Ballou [15]. Namely, mannan, $150 \mathrm{mg}$, was dissolved in $3 \mathrm{ml}$ of anhydrous formamide in 300-ml glass-stoppered round-bottomed flask, and the solution was added a 1:1 (v/v) mixture of $\left(\mathrm{CH}_{3} \mathrm{CO}\right)_{2} \mathrm{O}$ and anhydrous pyridine, $100 \mathrm{ml}$. The clear solution was kept at $40^{\circ} \mathrm{C}$ for $24 \mathrm{hr}$. The resultant solution was then evaporated in vacuo to dryness to an oil diffusion pump. The residue was dissolved in a 10:10:1 (v/v/v) ratio of mixture of $\left(\mathrm{CH}_{3} \mathrm{CO}\right)_{2} \mathrm{O}, \mathrm{CH}_{3} \mathrm{COOH}$, and $\mathrm{H}_{2} \mathrm{SO}_{4}, 150 \mathrm{ml}$, and the resultant solution was kept at $40^{\circ} \mathrm{C}$ for $13 \mathrm{hr}$. This solution was evaporated in vacuo to a thick syrup after addition of pyridine, $15 \mathrm{ml}$. The residue was extracted by $\mathrm{CHCl}_{3}, 50 \mathrm{ml}$, and the extract was washed with water, $100 \mathrm{ml}$ at three times. The $\mathrm{CHCl}_{3}$ layer was separated and dried over anhydrous $\mathrm{Na}_{2} \mathrm{SO}_{4}$. After filtration, the solution was evaporated in vacuo to dryness, and the residue was dissolved in anhydrous $\mathrm{CH}_{3} \mathrm{OH}, 2 \mathrm{ml}$. To the solution was added a few drops of $1 \mathrm{M}$ methanolic $\mathrm{CH}_{3} \mathrm{ONa}$ solution, and the mixture was left at room temperature until the precipitation of free sugars was accomplished. The mixture was then neutralized with $50 \%$ $\mathrm{CH}_{3} \mathrm{COOH}$ and evaporated in vacuo to dryness. The residue was dissolved in $2 \mathrm{ml}$ of water, applied to a column $(2.5 \times 100 \mathrm{~cm})$ of Bio-Gel P-2 (-400 mesh), and eluted with water $(0.25 \mathrm{ml} / \mathrm{min})$. Aliquots $(10 \mu \mathrm{l})$ of eluates were assayed for carbohydrate content by the phenol$\mathrm{H}_{2} \mathrm{SO}_{4}$ method [21]. Eluate corresponding to each peak was combined and concentrated in vacuo. In order to remove small amounts of contaminated oligosaccharides of lower and higher molecular weight, the solution was rechromatographed on the same column of Bio-Gel P-2, and eluates containing a homogeneous oligosaccharide were combined and lyophilized after concentration in vacuo.

\subsection{Calculation of Average Length of Side Chains and the Branching Frequency Value of Fr. C}

The average length of side chains $(X)$ and the branching frequency value $(Y)$ of Fr. C were calculated by using the following formula in accordance with previous descriptions [6]:

$$
\begin{aligned}
& X=[(\mathrm{A} \times 1)+(\mathrm{B} \times 2)+(\mathrm{C} \times 3)+(\mathrm{D} \times 4)] /(\mathrm{A}+\mathrm{B}+\mathrm{C}+\mathrm{D}) \\
& \text { and } \quad Y=[(\mathrm{B}+\mathrm{C}+\mathrm{D}) \times 100] /(\mathrm{A}+\mathrm{B}+\mathrm{C}+\mathrm{D})
\end{aligned}
$$

respectively, where $\mathrm{A}$ through $\mathrm{D}$ represent the molar proportions of mannose, biose, triose, and tetraose in the gel-filtration profile of the acetolysis products, and the numbers 1 through 4 indicate the degrees of polymerization of the mannose $\left(\mathrm{M}_{1}\right)$ and the three oligosaccharides, $\mathrm{M}_{2}$ through $\mathrm{M}_{4}$, respectively.

\section{5. ${ }^{1} \mathrm{H}$-Nuclear Magnetic Resonance $\left({ }^{1} \mathrm{H}-\mathrm{NMR}\right)$ Spectroscopy}

The NMR spectra conducted on a JEOL JNM-GSX 400 spectrometer at $400 \mathrm{MHz}$. It was recorded using a $0.5 \%$ $(\mathrm{w} / \mathrm{v})$ solution of each oligosaccharides in $0.7 \mathrm{ml}$ of $\mathrm{D}_{2} \mathrm{O}$ at $45^{\circ} \mathrm{C}$. Acetone (2.217 ppm) was used as an internal standard.

\subsection{Inhibition Test of Slide Agglutination Assay Using Oligosaccharides}

The inhibition assay of slide agglutination of $C$. catenulata cells with factor antibodies (FAbs) was conducted as previously described [13]. FAbs 1, 9, and 34 were prepared by Fukazawa et al. [1]. The inhibitor oligosaccharides, $\mathrm{M}_{2}, \mathrm{M}_{3}$ and $\mathrm{M}_{4}$, were obtained from Fr. $\mathrm{C}$ by acetolysis.

\section{Results and Discussion}

The oligosaccharides mixture obtained from Fr. C by acetolysis were fractionated with water by gel-chromatography of Bio-Gel P-2 (Figure 1). The large amounts of oligosaccharides, tetraose $\left(\mathrm{M}_{4}\right)$ and triose $\left(\mathrm{M}_{3}\right)$, and the small amounts of oligosaccharides, biose $\left(\mathrm{M}_{2}\right)$ and mannose $\left(\mathrm{M}_{1}\right)$, were eluted. No product eluted at the position of void-volume ( $\mathrm{Vo}$ ) indicates that all $\alpha-1,6$ linkages in Fr. $\mathrm{C}$ were completely cleaved by the acetolysis. The chemical structures of resultant oligosaccharides were analyzed by ${ }^{1} \mathrm{H}-\mathrm{NMR}$ spectroscopy. The $\mathrm{H}-1$ region signals of these oligosaccharides were shown in Figure 2. All spectra were identical to those of $\mathrm{M}_{2}, \mathrm{M}_{3}$, and $\mathrm{M}_{4}$, which were previously isolated from the cell wall mannans of Saccharomyces cerevisiae wild-type [22] and Candida glabrata [8]. The structure of $\mathrm{M}_{2}$ and $\mathrm{M}_{3}$ were 


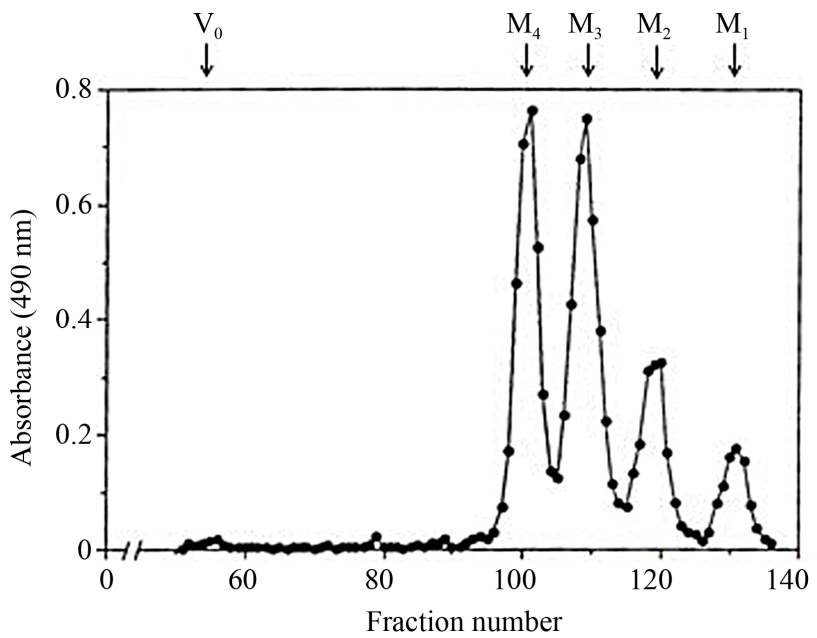

Figure 1. Elution profile of oligosaccharides obtained from C. catenulata mannan, Fr. C, by conventional acetolysis. Vo refers void-volume region. $M_{4}, M_{3}, M_{2}$ and $M_{1}$ indicate the eluted positions of standard monnooligosaccharides, tetraose, triose, and biose, and mannose, respectively.

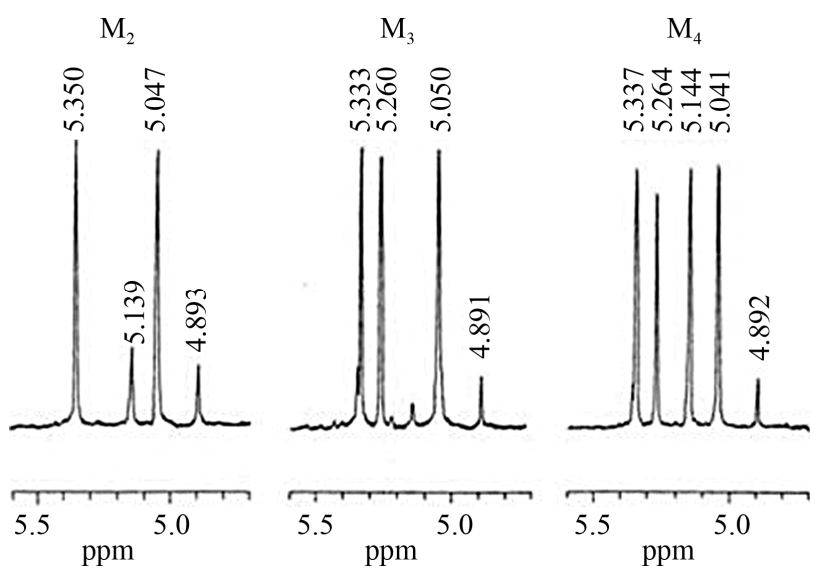

Figure 2. ${ }^{1} \mathrm{H}$-NMR spectra of oligosaccharides obtained from $C$. catenulata mannan, Fr. C, by conventional acetolysis. Simbols are the same as in Figure 1.

identified to Man $\alpha 1-2$ Man and Man 1 1-2Man $\alpha 1-2 M a n$, respectively. The H-1 signal at $5.144 \mathrm{ppm}$ in the spectrum of $\mathrm{M}_{4}$ indicates the presence of non-reducing terminal $\alpha$-1,3-linked mannose residue linked to $\alpha-1,2-$ linked oligomannosyl unit. Therefore, the structure of $\mathrm{M}_{4}$ was identified to Man $\alpha 1-3$ Man $\alpha 1-2$ Man $\alpha 1-2 M a n$. The chemical structure of all oligosaccharides and the assignment result of chemical shifts of all mannose residues based on the results of previous reports $[8,23]$ were shown in Table 1.

As shown in Table 2, to identify the antigenic determinants in C. catenulata mannan corresponding to antigenic factor, we performed an inhibition assay of agglutination between $C$. catenulata cells and factor antibodies, FAbs 1, 9, and 34, with three inhibitor oligosaccharides, $\mathrm{M}_{4}, \mathrm{M}_{3}$, and $\mathrm{M}_{2}$, and $\mathrm{M}_{1}$ (mannose) obtained from Fr. C
Table 1. Assignment of chemical shifts of $\mathrm{H1}$ signals of oligosaccharides obtained from $C$. catenulata mannan, Fr. C, by acetolysis.

\begin{tabular}{|c|c|c|c|c|c|c|c|c|}
\hline \multirow[t]{2}{*}{ oligosaccharide } & \multicolumn{4}{|c|}{ Sugar residue $\mathrm{a}^{\mathrm{a}}$} & \multicolumn{4}{|c|}{ Chemical shft (ppm) } \\
\hline & $\mathrm{D}$ & $\mathrm{C}$ & B & $\mathrm{A}(\alpha)^{\mathrm{c}}$ & $\mathrm{D}$ & $\mathrm{C}$ & B & $\mathrm{A}(\alpha)$ \\
\hline & & & & $\mathrm{A}(\beta)$ & & & & $\mathrm{A}(\beta)$ \\
\hline \multirow[t]{2}{*}{$\mathrm{M}_{2}$} & & & $\mathrm{M} \alpha$ & $-2 \mathrm{M}(\alpha)$ & & 5.047 & 5.350 & \\
\hline & & & $\mathrm{Mo}$ & $1-2 \mathrm{M}(\beta)$ & & 5.139 & 4.893 & \\
\hline \multirow[t]{2}{*}{$\mathrm{M}_{3}$} & & $\mathrm{M} \alpha$ & $-2 \mathrm{M} \alpha$ & $-2 \mathrm{M}(\alpha)$ & & 5.050 & 5.260 & 5.333 \\
\hline & & $\mathrm{M} \alpha$ & $-2 \mathrm{M} \alpha$ & $1-2 \mathrm{M}(\beta)$ & & 5.050 & 5.260 & 4.891 \\
\hline \multirow[t]{2}{*}{$\mathrm{M}_{4}$} & $\mathrm{M} \alpha$ & $-3 \mathrm{M} \alpha$ & $-2 \mathrm{M} \alpha$ & $-2 \mathrm{M}(\alpha)$ & 5.144 & 5.041 & 5.264 & 5.337 \\
\hline & $\mathrm{M} \alpha$ & $-3 \mathrm{M} \alpha$ & $-2 \mathrm{Mo}$ & $1-2 \mathrm{M}(\beta)$ & 5.144 & 5.041 & 5.264 & 4.892 \\
\hline
\end{tabular}

${ }^{\mathrm{a}} \mathrm{M}$ denotes a mannose residue; ${ }^{\mathrm{b}} \mathrm{This}$ was measured at $45^{\circ} \mathrm{C}$ using acetone (2.217 ppm) as a standard; ${ }^{\mathrm{C}} \mathrm{Configuration}$ of reducing terminal residue.

Table 2. Inhibition of agglutination of Candida catenulata cells with FAbs 1, 9, and 34 by mannooligosaccharides obtained from C. catenulata mannan, Fr. C.

\begin{tabular}{|c|c|c|c|c|c|c|}
\hline \multicolumn{7}{|c|}{ Agglutination ${ }^{\mathrm{a}}$ with inhibitor amt $(\mu \mathrm{mol})$} \\
\hline \multicolumn{7}{|c|}{ Oligosaccharide } \\
\hline & $2^{1}$ & $2^{0}$ & $2^{-1}$ & $2^{-2}$ & $2^{-3}$ & 0 \\
\hline \multicolumn{7}{|c|}{ With FAb 1} \\
\hline $\mathrm{M}_{1}$ & +3 & +3 & +3 & +3 & +3 & +3 \\
\hline $\mathrm{M}_{2}$ & +2 & +2 & +2 & +2 & +3 & +3 \\
\hline $\mathrm{M}_{3}$ & +1 & +1 & +1 & +2 & +3 & +3 \\
\hline $\mathrm{M}_{4}$ & +2 & +2 & +3 & +3 & +3 & +3 \\
\hline \multicolumn{7}{|c|}{ With FAb 9} \\
\hline $\mathrm{M}_{1}$ & +2 & +2 & +2 & +2 & +2 & +2 \\
\hline $\mathrm{M}_{2}$ & +2 & +2 & +2 & +2 & +2 & +2 \\
\hline $\mathrm{M}_{3}$ & +2 & +2 & +2 & +2 & +2 & +2 \\
\hline $\mathrm{M}_{4}$ & +2 & +2 & +2 & +2 & +2 & +2 \\
\hline \multicolumn{7}{|c|}{ With FAb 34} \\
\hline $\mathrm{M}_{1}$ & +3 & +3 & +3 & +3 & +3 & +3 \\
\hline $\mathrm{M}_{2}$ & +3 & +3 & +3 & +3 & +3 & +3 \\
\hline $\mathrm{M}_{3}$ & +3 & +3 & +3 & +3 & +3 & +3 \\
\hline $\mathrm{M}_{4}$ & +1 & +1 & +2 & +2 & +3 & +3 \\
\hline
\end{tabular}

${ }^{a}$ Agglutination was scored from high (+3) to low (+1).

by acetolysis. The fact that the antigen determinant of factor 9 could not be found in this experiment indicates this epitope does not reside in the side chains of Fr. C. On the other hand, the result with FAb 1 clearly indicates that two $\alpha-1,2$-linked oligomannosyl side chains corresponding to Man $\alpha 1-2$ Man and Man $\alpha 1-2$ Man $\alpha 1-2$ Man possess antigenic determinant of factors 1 . In contrast, FAb 34 unable to recognize $\alpha$-1,2-linked oligomannnosyl side chain, whereas it recognized the side chain possessing terminal $\alpha$-1,3-linked mannose, Man $\alpha 1$-3Man $\alpha 1-2$ Man $\alpha 1-$ 2Man. 
The chemical structure of the cell wall mannan obtained from C. catenulara IFO 0745 strain (Fr. C) and the recognition sites of factor antibodies 1,9 , and 34 were proposed as shown in Figure 3. The side chain distribution was calculated using the peak-dimensions in the gel-filtration profile of the acetolysis products (Figure 3(a)). The molar ratios of tetraosyl side chain were distinctly lower than that previously calculated from the dimension of H-1 signals in the ${ }^{1} \mathrm{H}-\mathrm{NMR}$ spectrum of the same mannan (Figure 3(b)) [19]. The average length of side chains, 2.6, and the value of branching frequency, $77.1 \%$, calculated from the peak-dimension of elution pattern of acetolysates (Figure 1) were lower than comparison with those calculated by the signal dimension of NMR spectrum (average length: 3.0, branching frequency: $91.3 \%$ ). These findings showed that the acetolysis conditions make to cleave not only $\alpha-1,6$ linkage of backbone but also non-reducing terminal part of the relatively longer $\alpha$-linked side chains. In conclusion, although acetolysis is useful for the preparation of the oligosaccharides corresponding to side chains as haptens of immunochemical or biological function, the NMR analysis without using harsh procedure is useful for the detailed analysis for the distribution of side chains in the parent mannan.

In the previous study $[10,12]$, we demonstrated that the $\alpha$-1,2-linked mannooligosaccharides and the oligosaccharides containing a non-reducing terminal $\alpha-1,3-$ linked mannose residue corresponding to the epitopes of antigenic factors 1 and 34, respectively. In this study, we could prepare three oligosaccharides corresponding to the antigenic factors 1 and 34, Man $\alpha 1-2$ Man, Man $\alpha 1$ 2Mano1-2Man, and Man 1 1-3Man 1 1-2Man $\alpha 1-2$ Man, which were isolated from $\alpha$-1,6-linked polymannnosyl backbone of Fr. C by the selective cleavage method, acetolysis. Though Fr. C reacted weakly with FAb 9, we could not find the oligosaccharide which functions as an antigenic epitope of this antibody (Table 2). This pheno-

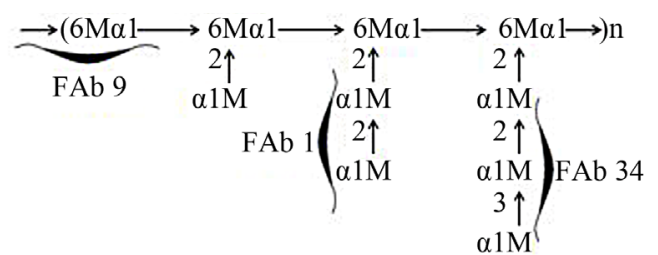

Side chain distribution

$\begin{array}{lrrrrrrr}\text { (a) } & 22.2 & : & 22.4 & : & 33.3 & : & 22.1 \\ \text { (b) } & 8.7 & : & 17.1 & : & 38.8 & : & 35.8\end{array}$

Figure 3. Structure of C. catenulata mannan, Fr. C, and recognition sites of factor antibodies, FAbs 1, 9, and 34 . (a) Side chain distribution was calculated based on the peakdimensions in the gel-filtration profile of the acetolysis products; (b) Side chain distribution was calculated based on the dimensions of characteristic $\mathrm{H1}$ signals of each side chain in the ${ }^{1} \mathrm{H}$-NMR spectroscopy map [19]. Side chain sequence is not specified. $M$ denotes a mannose residue. menon can explain that the site of factor 9 antibody is $\alpha-1,6$-linked polymannnosyl backbone of yeast mannnan in accordance with previous finding [12]. Namely, it is concluded that the most of mannose $\left(\mathrm{M}_{1}\right)$ released by acetolysis arose from the backbone part that is not connected by the side chain.

\section{REFERENCES}

[1] Y. Fukazawa, T. Shinoda and T. Tsuchiya, "Response and Specificity of Antibodies for Candida albicans," Journal of Bacteriology, Vol. 95, No. 3, 1968, pp. 754-763.

[2] T. Tsuchiya, Y. Fukazawa and S. Kawakita, "A Method for the Rapid Identification of the Genus Candida," Mycopathologia, Vol. 10, No. 3, 1959, pp. 191-206. doi:10.1007/BF02053014

[3] T. Tsuchiya, Y. Fukazawa, M. Taguchi, T. Nakase and T. Shinoda, "Serologic Aspects on Yeast Classification," Mycopathologia, Vol. 53, No. 1-4, 1974, pp. 77-92. doi:10.1007/BF02127199

[4] H. Kobayashi, N. Shibata, H. Mitobe, Y. Ohkubo and S. Suzuki, "Structural Study of Phosphomannan of YeastForm Cells of Candida albicans J-1012 Strain with Special Reference to Application of Mild Acetolysis," Archives of Biochemistry and Biophysics, Vol. 272, No. 2, 1989, pp. 364-375. doi:10.1016/0003-9861(89)90230-0

[5] N. Shibata, K. Ikuta, T. Imai, Y. Satoh, R. Satoh, A. Suzuki, C. Kojima, H. Kobayashi, K. Hisamichi and S. Suzuki, "Existence of Branched Side Chains in the Cell Wall Mannan of Pathogenic Yeast, Candida albicans. Structure-Antigenicity Relationship between the Cell Wall Mannans of Candida albicans and Candida parapsilosis," Journal of Biological Chemistry, Vol. 270, No. 3, 1995, pp. 1113-1122. doi:10.1074/jbc.270.3.1113

[6] H. Kobayashi, H. Oyamada, K. Matsuda, N. Shibata and S. Suzuki, "Distribution of Antigenic Oligomannosyl Side Chains in the Cell Wall Mannans of Several Strains of Candida tropicalis," Archives of Microbiology, Vol. 180, No. 1, 2003, pp. 76-80. doi:10.1007/s00203-003-0550-7

[7] N. Shibata, R. Akagi, T. Hosoya, K. Kawahara, A. Suzuki, K. Ikuta, H. Kobayashi, K. Hisamichi, Y. Okawa and S. Suzuki, "Existence of Novel Branched Side Chains Containing $\beta-1,2$ and $\alpha-1,6$ Linkages Corresponding to Antigenic Factor 9 in the Mannan of Candida guilliermondii," Journal of Biological Chemistry, Vol. 271, No. 16, 1996, pp. 9259-9266. doi:10.1074/jbc.271.16.9259

[8] H. Kobayashi, H. Oyamada, N. Iwadate, H. Szuki, H. Mitobe, K. Takahashi, N. Shibata, S. Suzuki and Y. Okawa, "Structural and Immunochemical Characterization of $\beta$-1,2-Linked Mannobiosyl Phosphate Residue in the Cell Wall Mannan of Candida glabrata," Archives of Microbiology, Vol. 169, No. 3, 1998, pp. 188-194. doi:10.1007/s002030050559

[9] N. Shibata, H. Kobayashi, Y. Okawa and S. Suzuki, "Existence of Novel $\beta$-1,2-Linkage-Containing Side Chain in the Mannan of Candida lusitaniae, Antigenically Related to Candida albicans Serotype A," European Journal of Biochemistry, Vol. 270, No. 12, 2003, pp. 25652575. doi:10.1046/j.1432-1033.2003.03622.x 
[10] H. Kobayashi, M. Komido, M. Watanabe, K. Matsuda, M. Suzuki, T. Ikeda, H. Oyamada, N. Shibata and S. Suzuki, "Structure of Cell Wall Mannan of Candida kefyr IFO 0586," Infection and Immunity, Vol. 62, No. 10, 1994, pp. 4425-4431.

[11] H. Ataoglu, J. Zueco and R. Sentandrew, "Characterization of Epitopes Recognized by Candida Factor 1 and 9 Antisera by Use of Saccharomyces cerevisiae mnn $\mathrm{Mu}-$ tants," Infection and Immunity, Vol. 61, No. 8, 1993, pp. 3313-3317.

[12] H. Kobayashi, H. Oyamada, A. Suzuki, N. Shibata, S. Suzuki and Y. Okawa, "Identification of the Antigenic Determinants of Factors 8, 9, and 34 of Genus Candida," FEBS Letters, Vol. 395, No. 2-3, 1996, pp. 109-112. doi:10.1016/0014-5793(96)01013-7

[13] N. Shibata, M. Arai, E. Haga, T. Kikuchi, M. Najima, T. Satoh, H. Kobayashi and S. Suzuki, "Structural Identification of an Epitope of Antigenic Factor 5 in Mannans of Candida albicans NIH B-792 (Serotype B) and C. albicans J-1012 (Serotype A) as $\beta$-1,2-Linked Oligomannosyl Residues," Infection and Immunity, Vol. 60, No. 10, 1992, pp. 4100-4110.

[14] H. Kobayashi, N. Shibata and S. Suzuki, "Evidence for Oligomannosyl Residues Containing both $\beta-1,2$ and $\alpha-1,2$ Linkages as a Serotype A-Specific Epitope(s) in Mannans of Candida albicans," Infection and Immunity, Vol. 60, No. 5, 1992, pp. 2106-2109.

[15] J. Kocourek and C. E. Ballou, "Method for Fingerprinting Yeast Cell Wall Mannans," Journal of Bacteriology, Vol. 100, No. 3, 1969, pp. 1175-1181.

[16] N. Shibata, H. Kobayashi and S. Suzuki, "Immunochemistry of Pathogenic Yeast Candida Species, Focusing on Mannan," Proceeding of the Japanese Academy Series B Physical and Biological Sciences, Vol. 88, No. 6, 2012, pp. 250-265. doi:10.2183/pjab.88.250

[17] A. Suzuki, N. Shibata, M. Suzuki, F. Saitoh, Y. Takata, A. Oshie, H. Oyamada, H. Kobayashi, S. Suzuki and Y. Okawa, "Characterization of $\alpha$-1,6-Mannosyltransferase
Responsible for the Synthesis of Branched Side Chains in Candida albicans Mannan," European Journal of Biochemistry, Vol. 240, No. 1, 1996, pp. 37-44. doi:10.1111/j.1432-1033.1996.0037h.x

[18] N. Shibata, and Y. Okawa, "Enzymatic Synthesis of New Oligosaccharides using Mannosyltransferases from Candida Species and Their NMR Assignment," Biological \& Pharmaceutical Bulletin, Vol. 33, No. 5, 2010, pp. 895899. doi: $10.1248 / \mathrm{bpb} .33 .895$

[19] H. Kobayashi, J. Suzuki, S. Tanaka, Y. Kiuchi, H. Oyamada, N. Iwadate, H. Suzuki, N. Shibata, S. Suzuki and Y. Okawa, "Structure of a Cell Wall Mannan from the Pathogenic Yeast, Candida catenulata: Assignment of ${ }^{1} \mathrm{H}$ Nuclear Magnetic Resonance Chemical Shifts of the Inner $\alpha$-1,6-Linked Mannose Residues Substituted by a Side Chain," Archives of Biochemistry and Biophysics, Vol. 341, No. 1, 1997, pp. 70-74. doi:10.1006/abbi.1997.9939

[20] H. Oyamada, Y. Ogawa, N. Shibata, Y. Okawa, S. Suzuki and H. Kobayashi, "Structural Analysis of Cell Wall Mannan of Candida sojae, a New Yeast Species Isolated from Defatted Soybean Flakes," Archives of Microbiology, Vol. 189, No. 5, 2008, pp. 483-890. doi:10.1007/s00203-007-0339-1

[21] M. Dubois, K. A. Gilles, J. K. Hamilton, P. A. Rebers and F. Smith, "Colorimetric Method for Determination of Sugars and Related Substances," Analytical Chemistry, Vol. 28, No. 3, 1956, pp. 350-356. doi:10.1021/ac60111a017

[22] H. Kobayashi, N. Shibata, M. Watanabe, M. Komido, N. Hashimoto, K. Hisamichi and S. Suzuki, "Mild Acetolysis and NMR Studies of the D-Mannan of Saccharomyces cerevisiae X2180-1A Wild-Type Strain," Carbohydrate Research, Vol. 231, 1992, pp. 317-323. doi:10.1016/0008-6215(92)84028-Q

[23] N. Shibata, A. Suzuki, Y. H. Kobayashi and Y. Okawa, "Chemical Structure of the Cell-Wall Mannan of Candida albicans Serotype A and Its Difference in Yeast and Hyphal Forms," Biochemical Journal, Vol. 404, No. 3, 2007, pp. 365-372. doi:10.1042/BJ20070081 